\section{Corps}

ui Liyureers

Waterways Experiment

Station

\title{
Centerline Discrepancies in HULL Axisymmetric Calculations
}

\section{by Amitabha Ghosh}

Rochester Institute of Technology

\author{
RESEARCH LIBRARY \\ US ARMY ENGINEER WATERWAYS \\ EXPERIMENT STATION \\ VICKSBURG, MISSISSIPPI
}




\section{Centerline Discrepancies in HULL Axisymmetric Calculations}

by Amitabha Ghosh

Rochester Institute of Technology

Department of Mechanical Engineering

Rochester, NY 14632

Final report

Approved for public release; distribution is unlimited

Prepared for Defense Nuclear Agency

Kirtland AFB, NM $87117-5000$

Under

Contract No. DAAL03-91-C-0034

Monitored by Structures Laboratory

U.S. Army Engineer Waterways Experiment Station

3909 Halls Ferry Road, Vicksburg, MS 39180-6199 


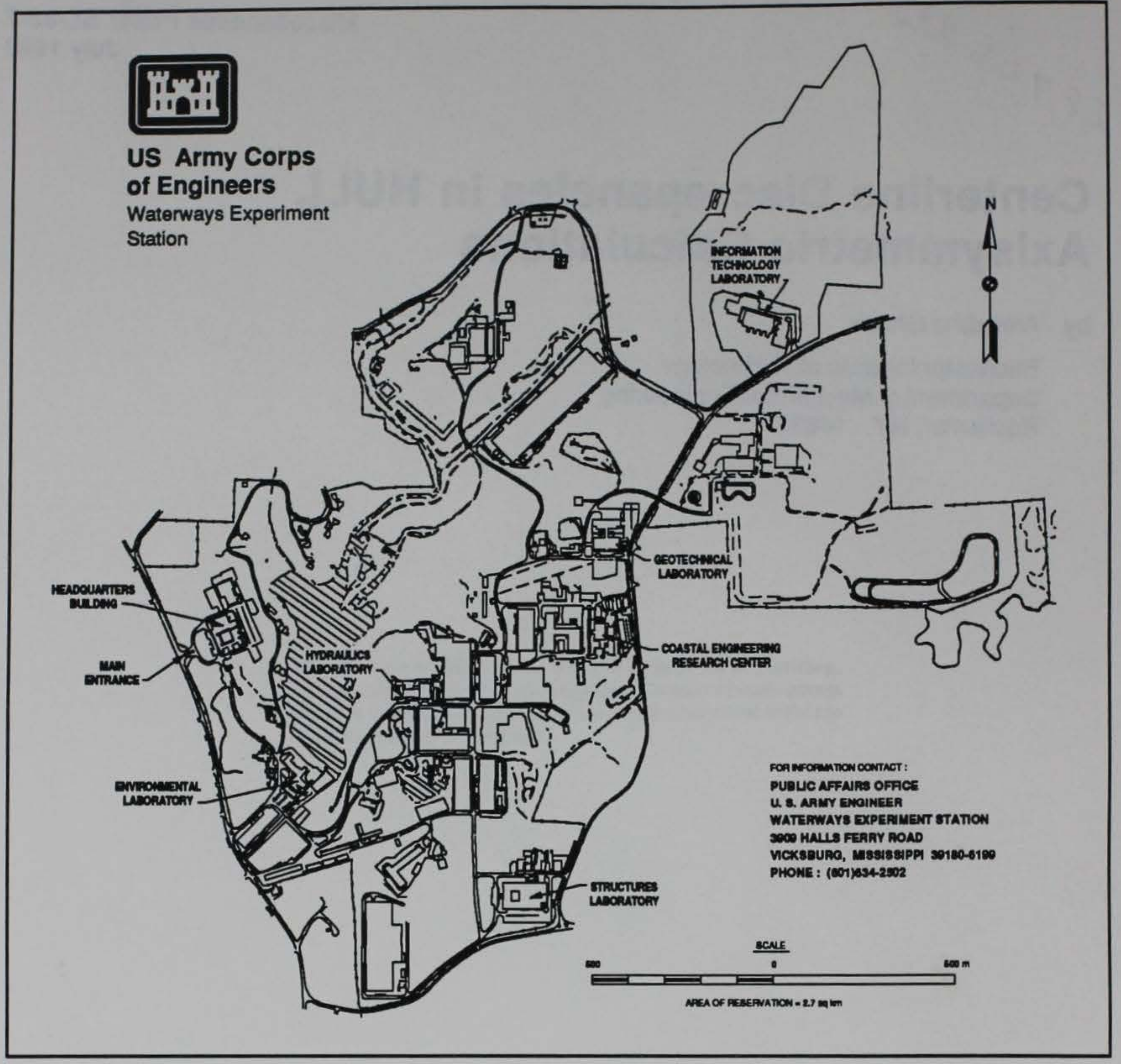

Waterways Experiment Station Cataloging-In-Publication Data

Ghosh, Amitabha.

Centerline discrepancies in HULL axisymmetric calculation / by

Amitabha Ghosh ; prepared for Defense Nuclear Agency ; monitored by

Environmental Laboratory, U.S. Army Engineer Waterways Experiment

Station.

30 p. : ill. ; $28 \mathrm{~cm}$. - (Miscellaneous paper ; SL-93-7)

1. Blast effect - Data processing. 2. Aerodynamic load - Computer programs - Evaluation. 3. Symmetric functions. 4. HULL (Computer program) I. United States. Defense Nuclear Agency. II. U.S. Army Engineer Waterways Experiment Station. III. Title. IV. Series: Miscellaneous paper (U.S. Army Engineer Waterways Experiment Station) ;

SL-93-7.

TA7 W34m no.SL-93-7 
The work described in this report was sponsored by Field Command, Defense Nuclear Agency (FCDNA). Funding was provided under MIPR No. HD1102-1-H24A03 and HD1102-1-H42K03.

The research was conducted by Dr. A. Ghosh, Rochester Institute of Technology, under a Scientific Services Agreement issued by Battelle, Contract No. DAAL03-91-C-0034, Task Control No. 92-007, Delivery Order No. 0084, for the Explosion Effects Division (EED), Structures Laboratory (SL), U.S. Army Engineer Waterways Experiment Station (WES).

This research effort was under the overall direction of Messrs. C. R. Welch and H. G. White, EED. Mr. L. K. Davis was Chief, EED, and Mr. Bryant Mather was Director, SL.

At the time of publication of the report, Director of WES was Dr. Robert W. Whalin. Commander was COL Leonard G. Hasse11, EN. 


\section{Contents}

Preface.....................

List of Figures $\ldots \ldots \ldots \ldots \ldots \ldots \ldots \ldots \ldots \ldots \ldots \ldots \ldots \ldots \ldots \ldots \ldots$

Introduction $\ldots \ldots \ldots \ldots \ldots \ldots \ldots \ldots \ldots \ldots \ldots \ldots \ldots \ldots \ldots \ldots \ldots$

Analytical Formulation $\ldots \ldots \ldots \ldots \ldots \ldots \ldots \ldots \ldots \ldots \ldots$

Numerical Experiments. $\ldots \ldots \ldots \ldots \ldots \ldots \ldots \ldots \ldots \ldots \ldots$

Discussion of Results.................

Conclusions $\ldots \ldots \ldots \ldots \ldots \ldots \ldots \ldots \ldots \ldots \ldots \ldots \ldots \ldots \ldots \ldots \ldots \ldots \ldots \ldots$

Appendix: SAIL Input for Figures $3-12 \ldots \ldots \ldots \ldots \ldots$ 
Figure

Page

1 Mineral Find 2 test configuration.............

2 Original Velocity Vector and Pressure Contour Plot. 8 (reproduced from Reference 1)

3 Split Panel Plots for Test Calculation No. 1......9 (old calculations)

4 Station Plot at Ground Zero for Test Calculation

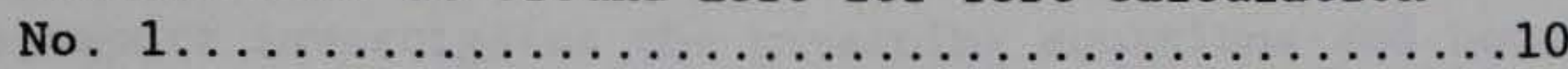

5 Split Panel Plots for Test Calculation No. 2.....11 (boundary flux correction applied)

6 Station Plot at Ground Zero for Test Calculation

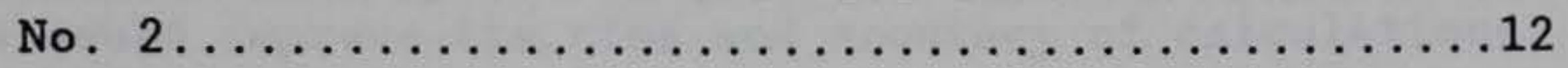

7 Split Panel Plots for Test Calculation No. 3.....13 (boundary flux plus average density applied)

8 Station Plot at Ground Zero for Test Calculation

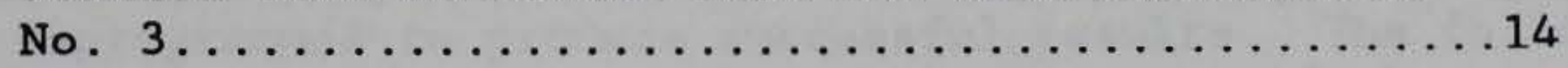

9 Split Panel Plots for Test Calculation No. 4.....15 (specific energy equation modified)

10 Station Plot at Ground Zero for Test Calculation

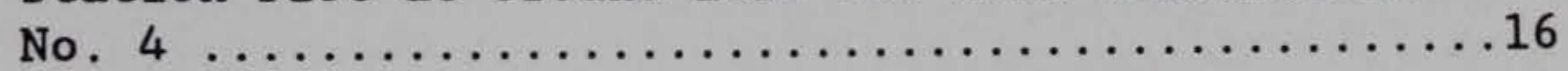

11 Split Panel Plots for Test Calculation No. $5 \ldots \ldots \ldots 17$ (specific energy and velocity equations modified)

12 Station Plot at Ground Zero for Test Calculation

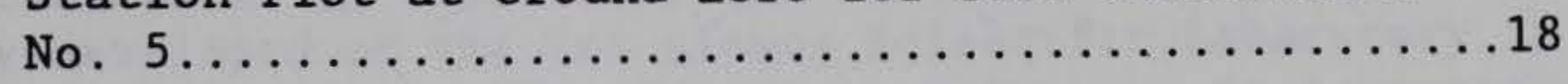


This investigation was prompted by a previous report ${ }^{1}$, describing airblast calculations made with the HULL hydrocode for the MINERAL FIND 2 explosion test, involving a sphere of radius $38 \mathrm{~cm}$, packed with the explosive HMX and detonated at $304.8 \mathrm{~cm}$ above ground (Figure 1). A plot of pressure contours and velocity vectors (Figure 2) show a peculiar jetlike behavior in pressure and velocity at $t=0.75 \mathrm{msec}$. The HULL hydrocode is a versatile and robust code, widely used for compressible flow calculations. Based on previous experience, the jet-like behavior is certainly not expected. At first glance, boundary conditions are suspected to be the primary cause of this anomaly.

This report investigates the governing equations and boundary conditions that are used in the HYDRO subroutine in the Eulerian, two-dimensional calculation mode of HULL. It was our primary focus given the limited time of the investigation. In this respect, velocity, pressure and stress boundary conditions were checked and, if necessary, modified. It was anticipated that correcting errors in the boundary conditions would improve the time and accuracy of calculations.

The investigation used a constant subgrid of mesh width $0.5 \mathrm{~cm}$ between $\mathrm{x}=0$ and $35 \mathrm{~cm}$ for all trial runs. This overcomes the grid dependency of the scheme developed. First velocity, then stress boundary conditions were modified and tested. Eventually the governing equations had to be reprogrammed to produce successful results. The following sections present the analytical theory, a discussion of the computational and experimental results, and concluding remarks. The appendix shows the SAIL commands implemented in this investigation.

\section{Analytical Formulation}

The analytical formulation of the HULL hydrocode is based on a mixture of Particle in Cell (PIC) and Fluid in Cell (FLIC) codes originally developed at the Los Alamos Scientific Laboratory in New Mexico by the T-3 group. The code is very large. It is unnecessary to report all the details here. We shall, however, focus on the governing equations and boundary conditions in the subroutine HYDRO. For axisymmetric flows, the continuity and momentum equations are given by -

1 C. W. Mastin, "Mineral Find 2 Airblast Calculations", Report presented at the Airblast Calculations Meeting, U.S. Army Engineer Waterways Experiment Station, Vicksburg, MS, 16 January, 1991 , pp. B $1-18$. 


$$
\begin{aligned}
& \frac{\partial \rho}{\partial t}+\frac{\partial\left(\rho V_{x}\right)}{\partial I}+\frac{\partial\left(\rho V_{z}\right)}{\partial z}+\frac{\rho V_{x}}{I}=0 \\
& \rho \frac{D V_{x}}{D t}=\rho B_{x}+\frac{1}{I} \frac{\partial\left(I \sigma_{x x}\right)}{\partial I}+\frac{\partial \tau_{x z}}{\partial z} \\
& \rho \frac{D V_{z}}{D t}=\rho B_{z}+\frac{1}{I} \frac{\partial\left(I \tau_{x z}\right)}{\partial I}+\frac{\partial \sigma_{z z}}{\partial z}
\end{aligned}
$$

where, $V_{r}$ and $V_{z}$ are velocity components in radial and axial directions, $B_{r}$ and $B_{z}$ represent body force per unit mass along $r$ and $z, \rho$ is the density and $D / D t$ has the usual meaning of the substantial derivative. The energy equation can be written similarly using velocity and stress components.

In the above set of equations, (2) and (3) are called the Navier's equations. They are usually cast into the Navier-Stokes form using the Stokes' hypothesis relating stresses to the strain rates, before the above set can be solved for velocity components. In the HULL context, however, we shall retain them in their stress forms.

Whether we solve the governing equations in the Navier-Stokes form or retain Navier's form, we have to specify boundary conditions in velocity and stress components along the boundaries of the physical domain, and, as in the context of a time dependent problem, specify initial conditions. Of particular interest are the boundary conditions along the line of symmetry in axisymmetric calculations.

There are several possible ways the governing equations in the finite difference form. The HULL hydrocode utilizes the explicit calculation mode, where velocity components are expressed at the edges of a computational cell and pressure and stress components are expressed at the cell center.

Though explicit difference schemes have the drawback of small time steps, this particular code has superior stability properties due to the "zip" type differencing utilized in the finite differencing mode. This feature also maintains the second order accuracy, even with linear interpolations. The details of the donor cell differencing are widely available in literature and therefore are not presented here.

The calculation in HULL proceeds in two steps, with intermediate values necessary at time step $\left(n+\frac{1}{2}\right)$. In the first phase of calculation, convection in terms of particle transport is not allowed. The finite difference expressions are written for the density and velocity ( $r$ and $z$ components) equations, (1) through (3). In addition, the finite difference forms for the specific energy and pressure equations are derived from: 


$$
\begin{gathered}
\rho \frac{D e}{D t}=\frac{1}{r} \frac{\partial\left(r \sigma_{x x} V_{x}\right)}{\partial r}+\frac{\partial\left(\sigma_{z z} V_{z}\right)}{\partial z}+\frac{1}{I} \frac{\partial\left(r \tau_{x z} V_{z}\right)}{\partial r}+\frac{\partial\left(\tau_{x z} V_{x}\right)}{\partial z}+\rho(\vec{B} \cdot \vec{V}) \\
\frac{D p}{D t}=-\rho c^{2}(\nabla \cdot \vec{V})
\end{gathered}
$$

In the above expressions, $e$ is the specific energy, $c$ is the local speed of sound in the medium and $p$ is the pressure. The other variables have the usual meanings as before. In addition to the above equations, suitable equations of state are used depending on the problem.

At this stage, equations (1) through (5) must be cast into finite difference forms. Although explicit differencing can be used, self adjoint or conservative forms must be maintained in differencing for superior error properties. This is the reason why the usual flux differencing of radial stress terms is replaced by a difference between radial and hoop stresses in quasi one-dimensional calculations. The above two differencing methods, however, do not differ significantly in axisymmetric calculations as were tested here.

The above equations are solved with the help of two types of boundary conditions for reflective and transmissive boundaries. In either case, additional cell values for fictitious cells are calculated and stored. For rigid surfaces, the cells adjacent to them must ensure no flow of mass or energy across the boundary. Thus, normal velocity components across a rigid cell must be zero and the tangential velocity components must be preserved. This same idea pervades in normal and tangential stress evaluations. The free surfaces must be free of stresses also. Since the calculations are performed for inviscid flows, the boundary conditions at a rigid surface become synonymous with those at a plane of symmetry. To keep the method flexible, similar differencing as in the equations above, using hoop stresses, were developed in the HULL code.

\section{Numerical Experiments}

A thorough visual check of the governing equations and boundary conditions was made prior to the numerical simulation. The size of HULL often prohibits detection of certain anomalies just by theoretical checks. In a large code such as this, errors do happen sometimes inadvertently. However, if no such obvious errors are found, the only means to identify the error is through numerical experiments. One advantage of the current code is that it is very robust. Minor errors by 
the programmer are often forgiven. However, from another standpoint, it becomes even harder to make the program fail due to the tweaking of certain inputs.

In performing the numerical experiments, the author preferred to use a theoretical basis, rather than rules of the trade, to decide further course of action. For example, though experience shows that the use of the difference between radial and hoop stresses may be substituted in place of radial conservative differencing (due to better error cancellation), this is not the general practice in calculations of 2-D cylindrical geometry. Therefore an attempt was made to first cast the formulation the way it should be, before special observations such as this could be made.

Some features of the HULL calculation scheme were retained and some modified during the course of this investigation. For example, the use of the minimum value of $\rho c^{2}$ was retained for failure calculations. However, the use of maximum $\rho$ in divergence calculations was replaced in some runs by an average $\rho$.

The boundary conditions were checked first. Apparently there were no mistakes. Several cases of boundary conditions were tested. These included intermediate time step boundary calculations with and without particle transport. This was done to determine the sensitivity of intermediate boundary values on the final results.

In some experiments, the boundary conditions on the centerline axis of symmetry were cast in the same form that the fundamental differencing scheme utilizes to treat the right reflective boundary. It should be noted that, in a cell calculation, the left and right boundaries of the cell must conform to each other in transporting a material property.

Finally, when no significant improvement in the centerline jet behavior was produced by the use of modified boundary conditions, governing equations were reprogrammed. This eventually identified the problem in the specific energy equation as described in the discussion of results. For conciseness, only a relevant summary will be presented in the next section.

\section{Discussion of Results}

The data in question are the velocity vector and pressure plots along the centerline in axisymmetric calculations. The original data (reported in Reference 1 and shown in Figure 2) were recreated by the author. For investigative purposes, all test runs were made with the airblast calculations of the same HMX detonation problem. This first set of results identifying the original calculation is called Test Calculation No. 1, and shown in Figures 3 and 4 . Figure 3 shows the 
split panel plots of velocity vectors and pressure contours at time $t=$ $0.75 \mathrm{~ms}$. We observe spurious jet like behavior in the velocity vector plot along the centerline, where no physical influence on the flow is present. The pressure contour plots on the left panel confirm this behavior. Figure 4 shows the corresponding station plot at ground zero for this calculation. Present calculation of pressure versus time is shown by the solid line. This plot also shows two broken line plots of experimental data at the same ground zero location. The shorter broken lines show the behavior of Airblast Gage No. 48 (AB-48) data (peak overpressure of $93 \mathrm{MPa}$ ), and the longer broken lines show the behavior of the AB-47 data (peak overpressure of $37 \mathrm{MPa}$ ). For comparison purposes, all test calculations will be presented with these two experimental data plots. The wave forms generated by HULL calculations traditionally lag the experimental data in arrival time. Therefore the abscissa of the calculational results has been shifted by $200 \mu \mathrm{s}$ in all plots of this type.

It may be mentioned that, although the test runs were made from time $t=0$ to $t=2.3 \mathrm{msec}$, and in some cases up to $t=3.3 \mathrm{msec}$, for comparison sake, only data at $t=0.75 \mathrm{msec}$ will be compared. In the early part of this investigation, temporal growth of the artifacts were studied at different times. It was found that this behavior was less prominent after the shock interacted with the ground. However, in some cases, although obscure, the centerline vectors show up in a single streak, even after reflection of the shock from the ground.

As mentioned before, the author wished to determine if radial flux differencing would improve calculations in 2-D axially symmetric problems. With flux terms cast the same way in the left and right boundaries, the results produced visible improvements in velocity vectors and station plots, as shown in Figures 5 and 6 (Test Calculation No. 2). This input uses stress values on the left boundary set at zero. The peak overpressure seems to attain a better value with this approach.

The best peak overpressure was obtained in the next case (Figures 7 and 8 , Test Calculation No. 3), where average densities are used instead of maximum densities in divergence terms, when compared with the previous test case.

Several variations of governing equation and boundary conditions in velocity and stresses were run. However, in all those results, velocity seemed to have a lingering snag, still near the axis of symmetry as apparent in both the Figures 5 and 7 . Therefore those additional results are not presented here.

After considerable testing failed to eliminate the jetlike feature at the centerline, focus was shifted from the velocity and pressure to the specific energy calculations. This was for the simple reason that although pressure looked reasonable (compare Figure 3 with Figures 5 or 7 ), velocity still seemed to be having an adjustment problem from elsewhere, which points to the specific energy. Finally, it turned out that only those changes required to fix the artifacts were in the 
specific energy equation. The next four figures $(9-12)$ show the changes implemented in the radial differencing terms of the specific energy equation. Figures 9 and 10 (Test Calculation No. 4) are for this single change in the original HULL code. Figures 11 and 12 (Test Calculation No. 5) reflect the case of radial conservative differencing in velocity equations as well. Figures 9 and 11 both show correct plots of velocity vectors and pressure. However, the station plots have changed in these runs characteristically. Now the peak pressure comes much later. At this time, it is unknown whether the fixing of the velocity artifacts has more merit over the behavior of the station plots. This phenomenon needs to be further investigated to improve HULL calculation capabilities for investigating this type of explosion problem.

\section{Conclusions}

A series of numerical experiments were performed to determine the cause of centerline artifacts in HULL axisymmetric calculations. Although it appeared originally to be a problem of velocity or pressure boundary conditions, the jetlike artifacts were found to be caused by the specific energy equation. At this stage, the centerline instability problem has been rectified. However, station plots show that earlier versions appear to have better pressure transients. Further investigations are necessary to improve the pressure calculations. 


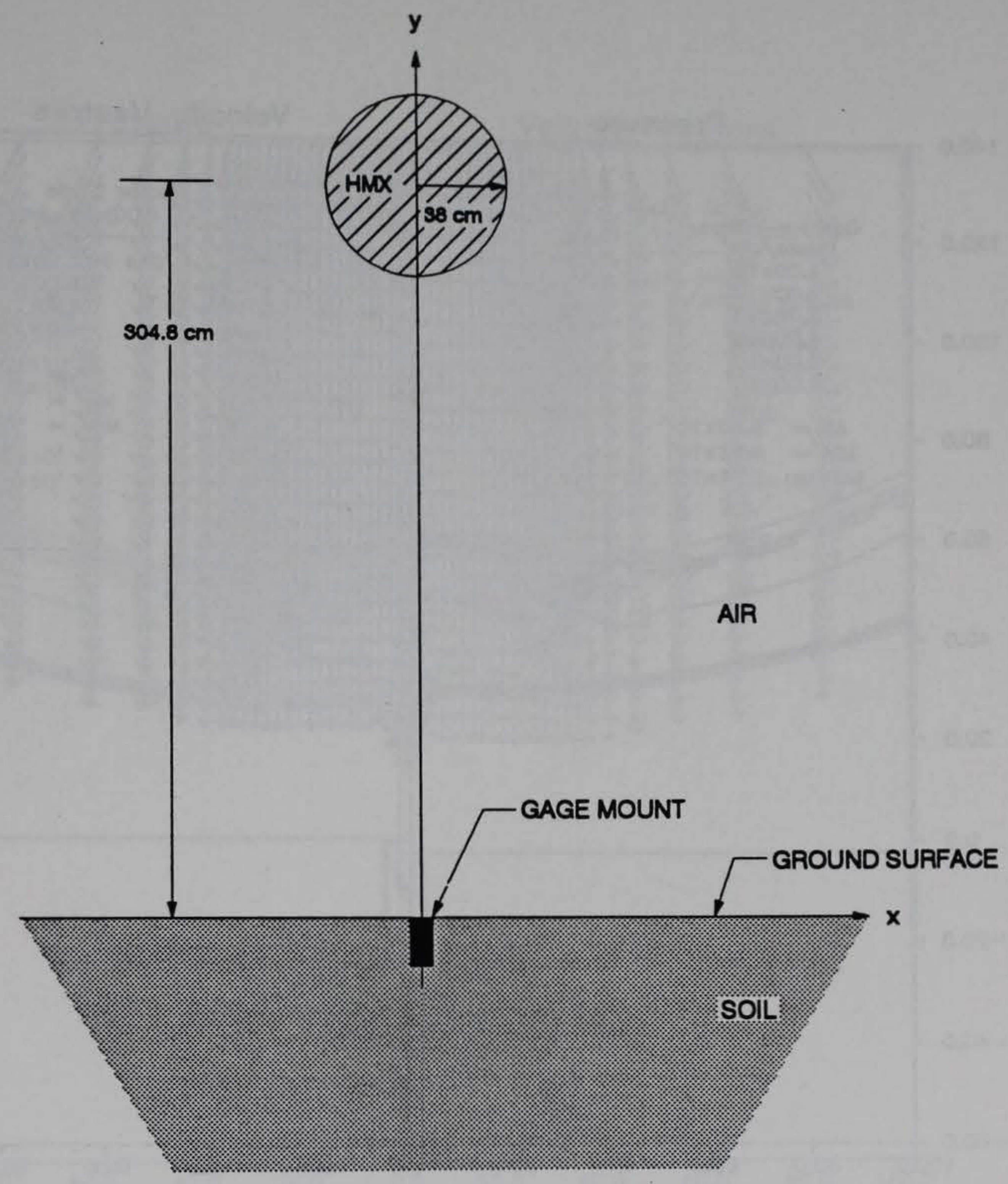

Figure 1. Mineral Find 2 test configuration 


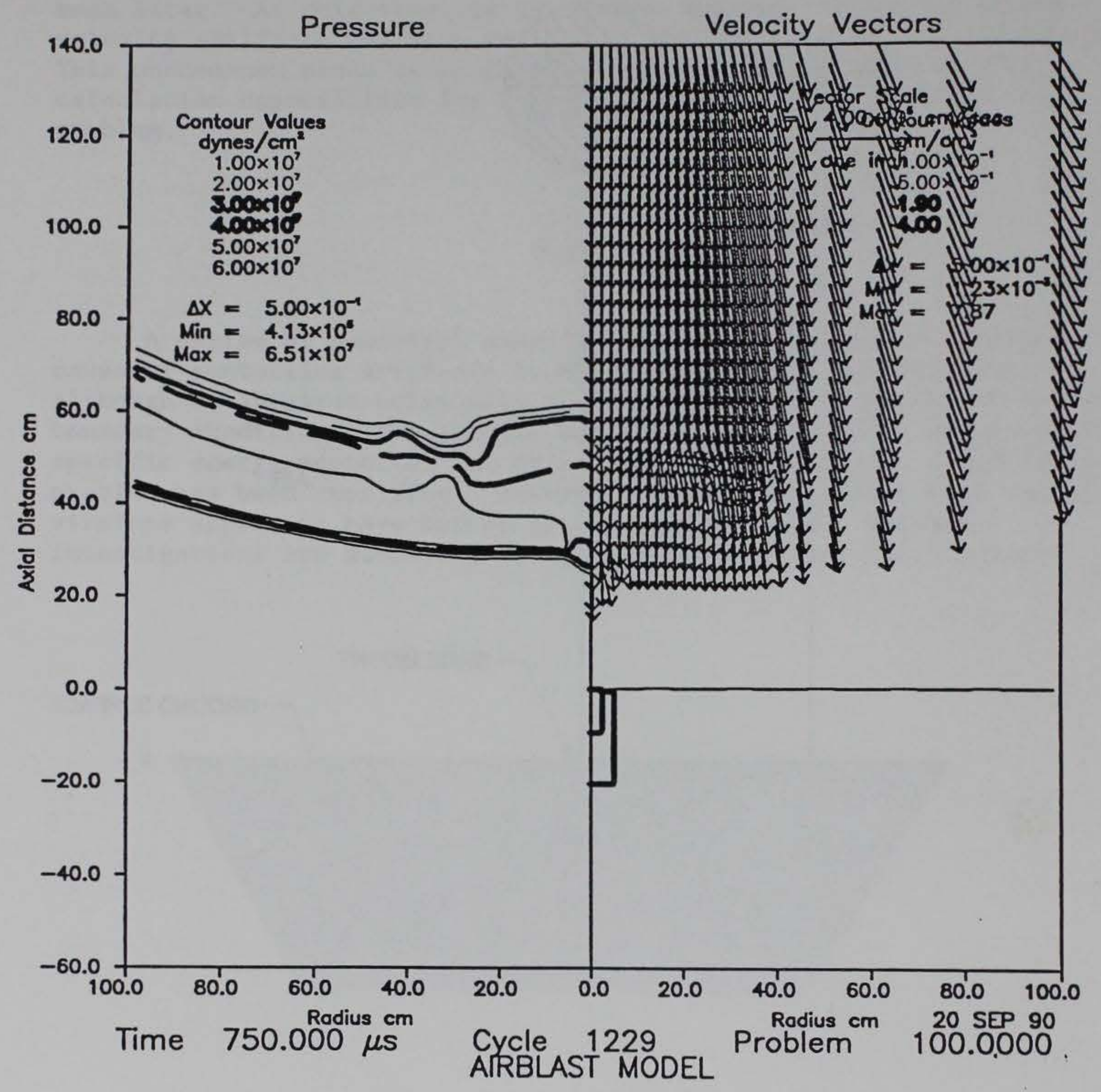

Figure 2. Original Velocity Vector and Pressure Contour Plot (reproduced from Reference 1) 


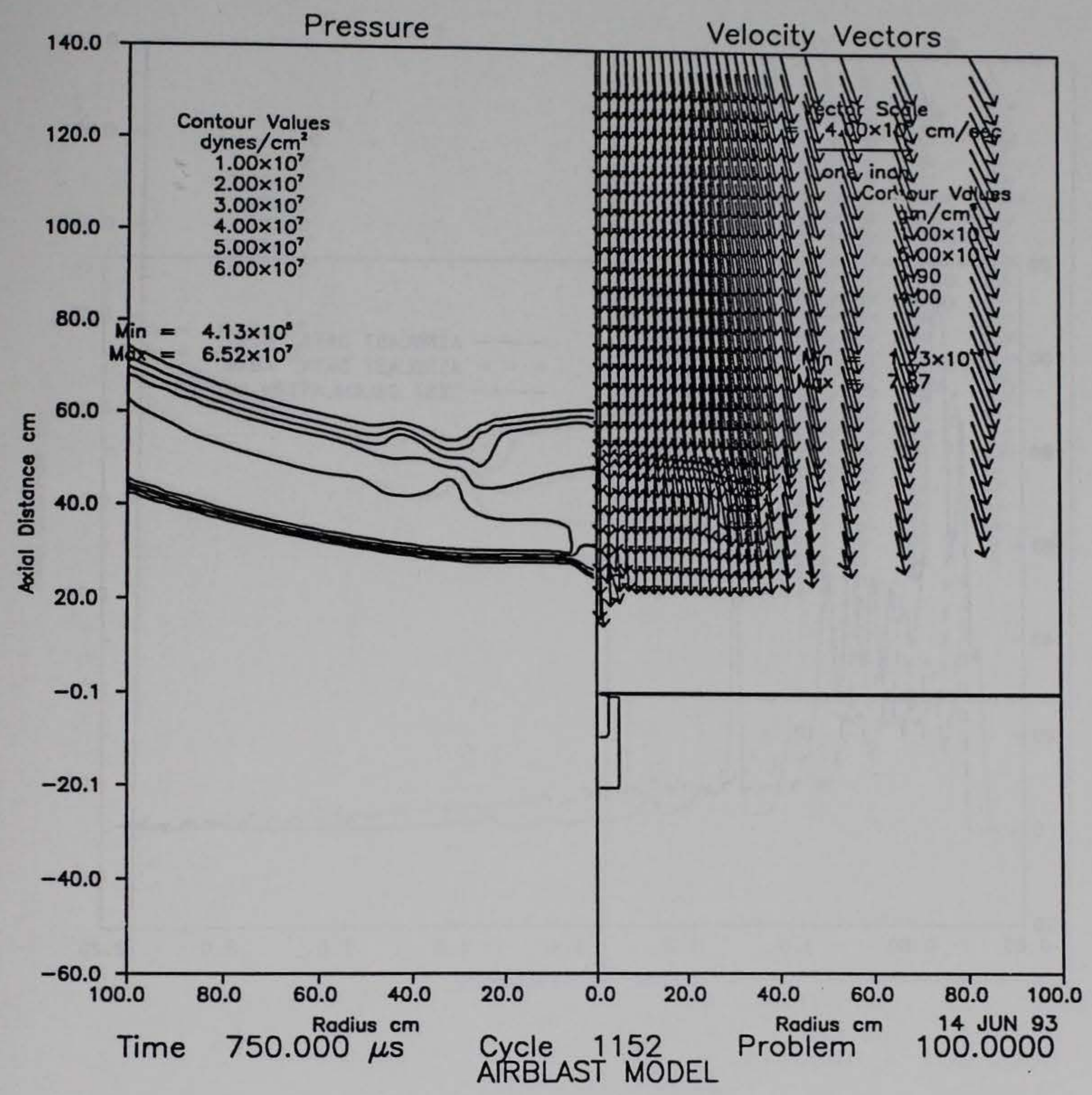

Figure 3. Split Panel Plots for Test Calculation No. 1 (old calculations) 


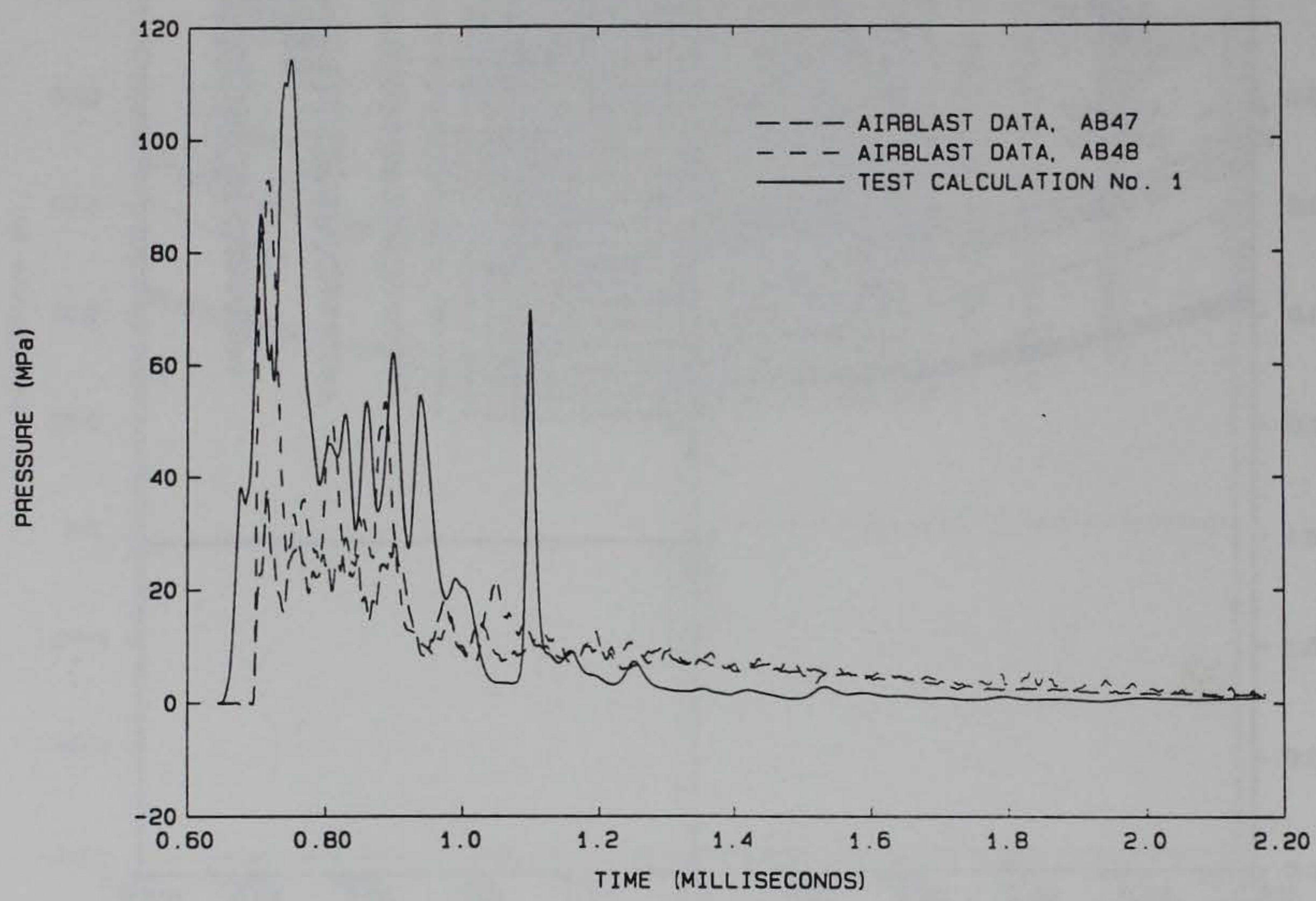

Figure 4. Station Plot at Ground Zero for Test Calculation No. 1 


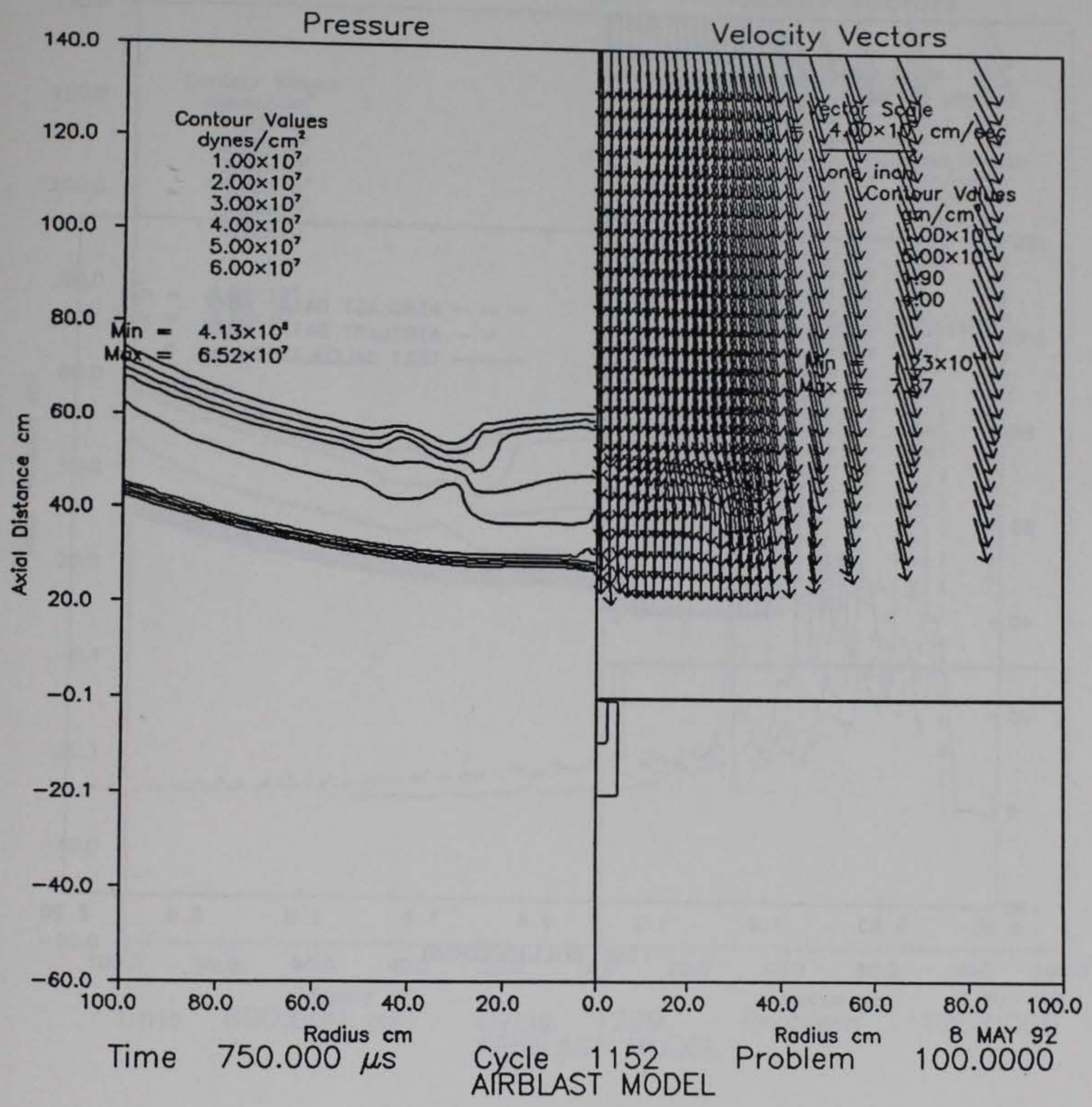

Figure 5. Split Panel Plots for Test Calculation No. 2 (boundary flux correction applied) 


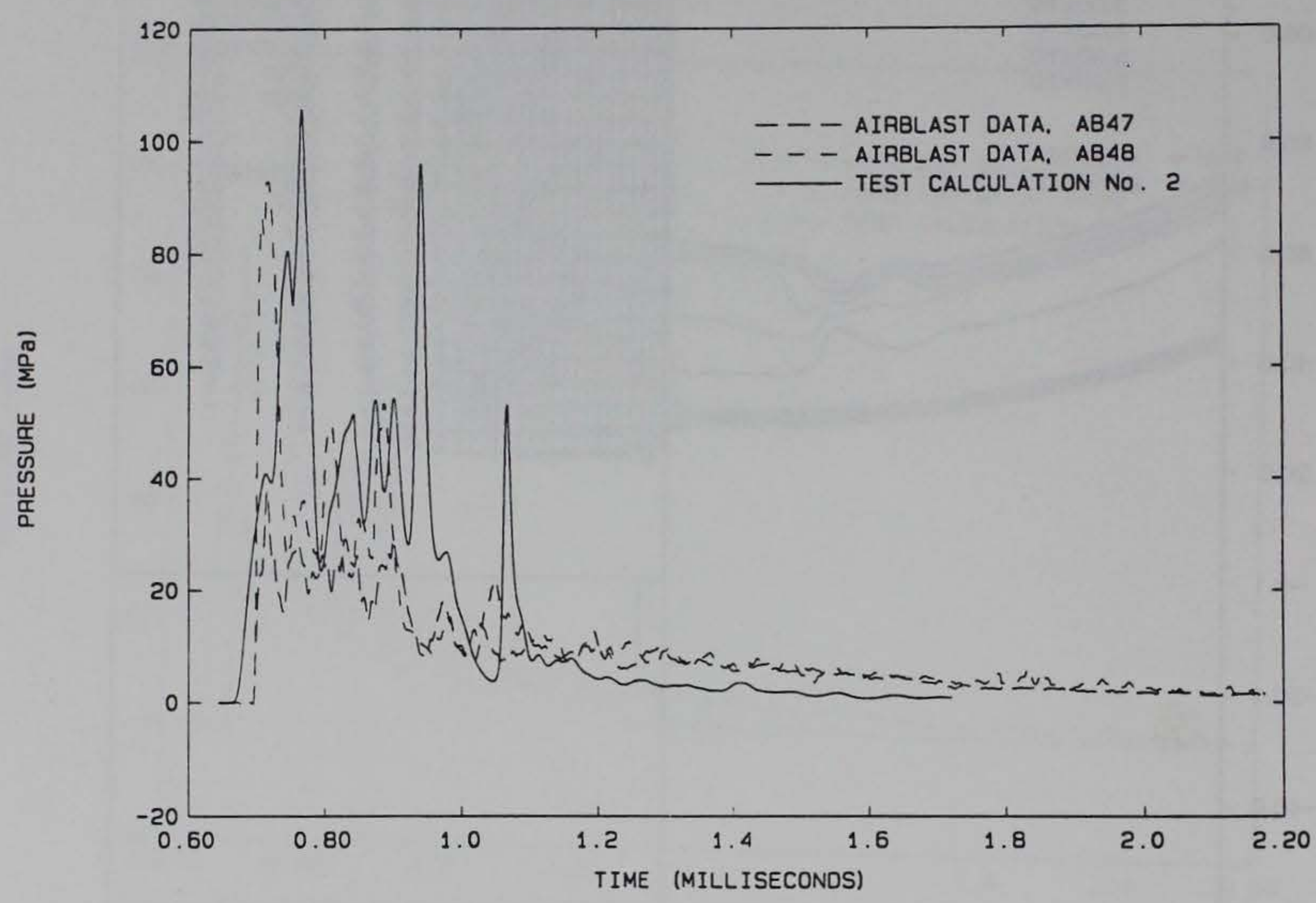

Figure 6. Station Plot at Ground Zero for Test Calculation No. 2 


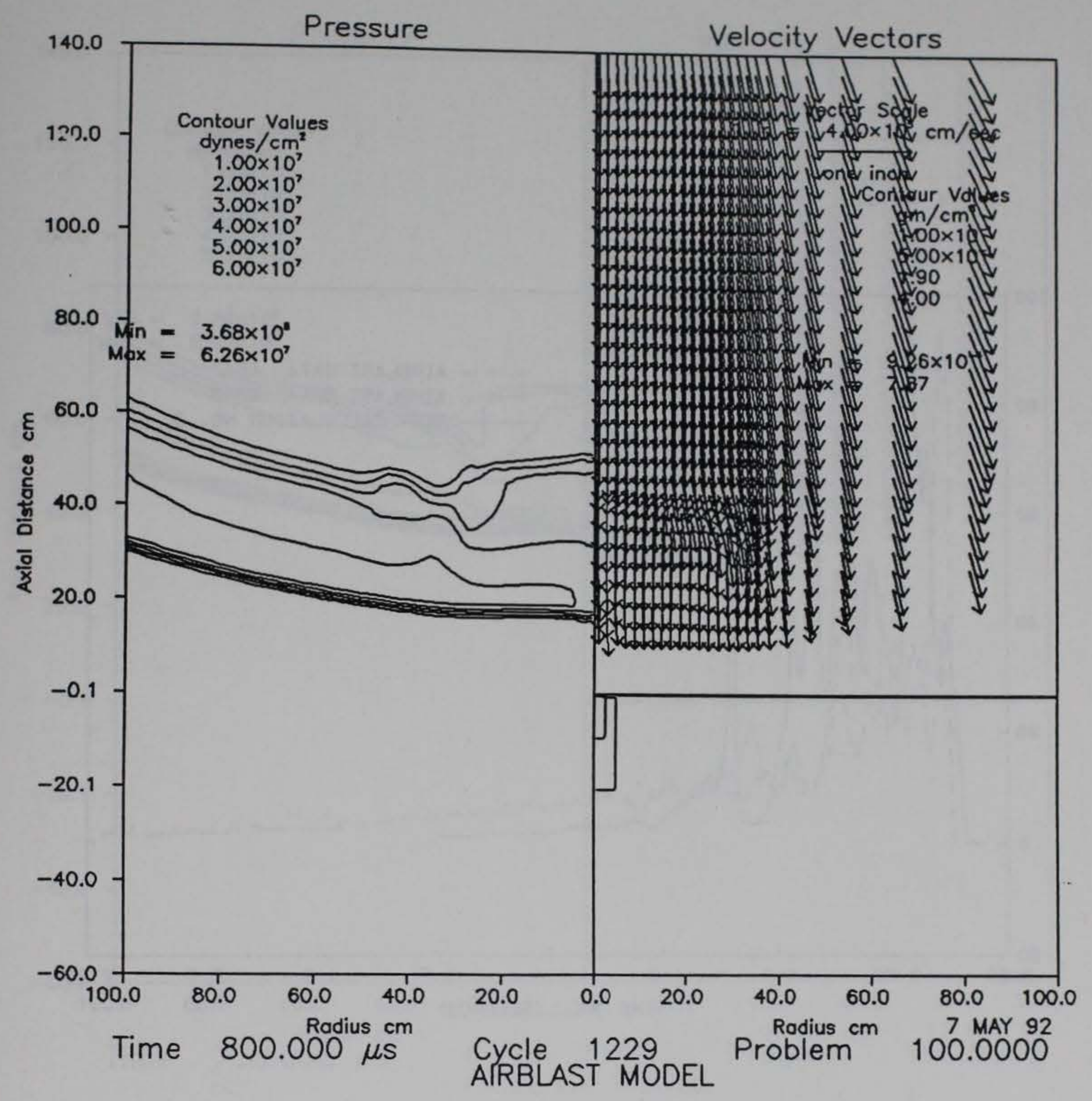

Figure 7. Split Panel Plots for Test Calculation No. 3 (boundary flux plus average density applied) 


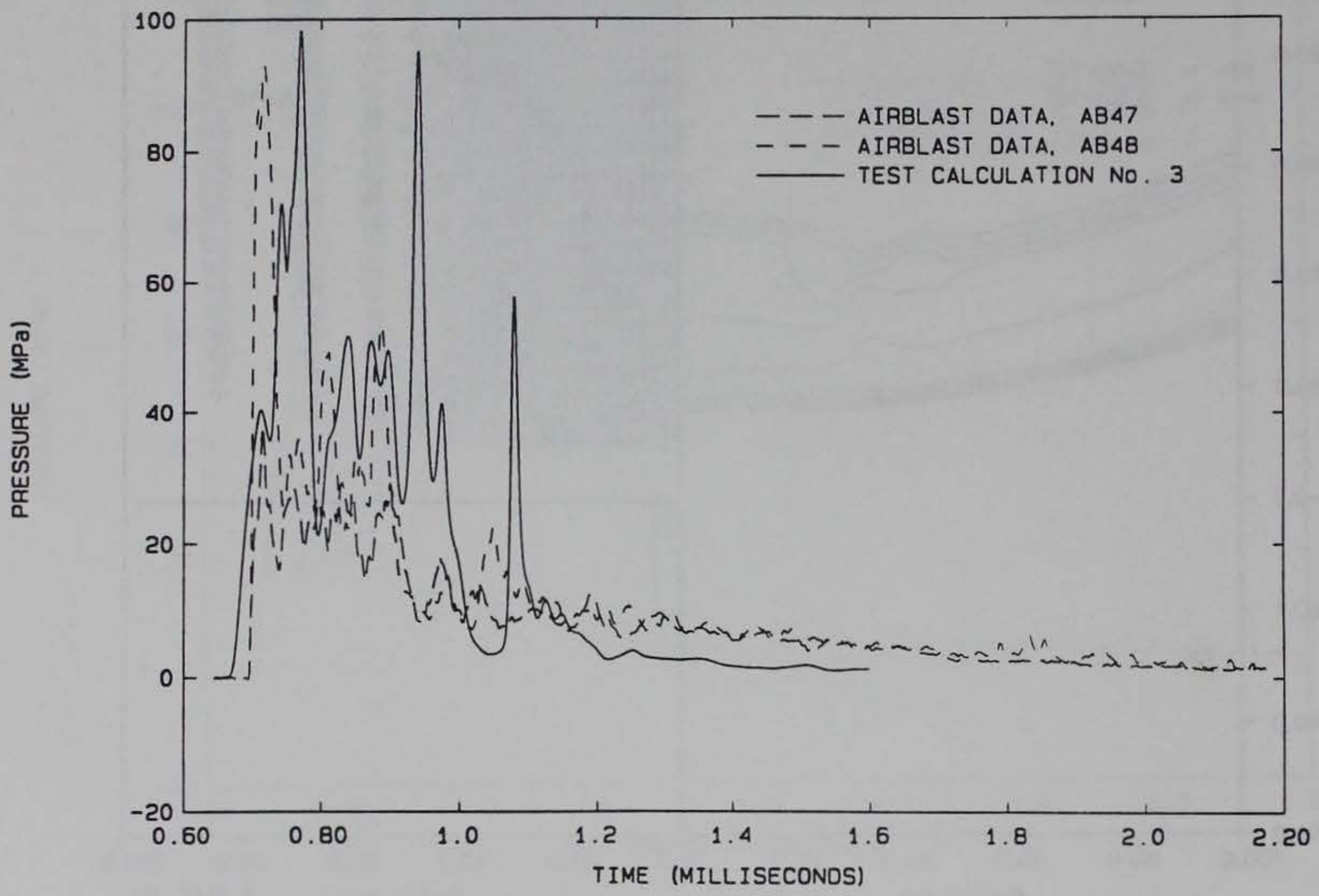

Figure 8. Station Plot at Ground Zero for Test Calculation No. 3 


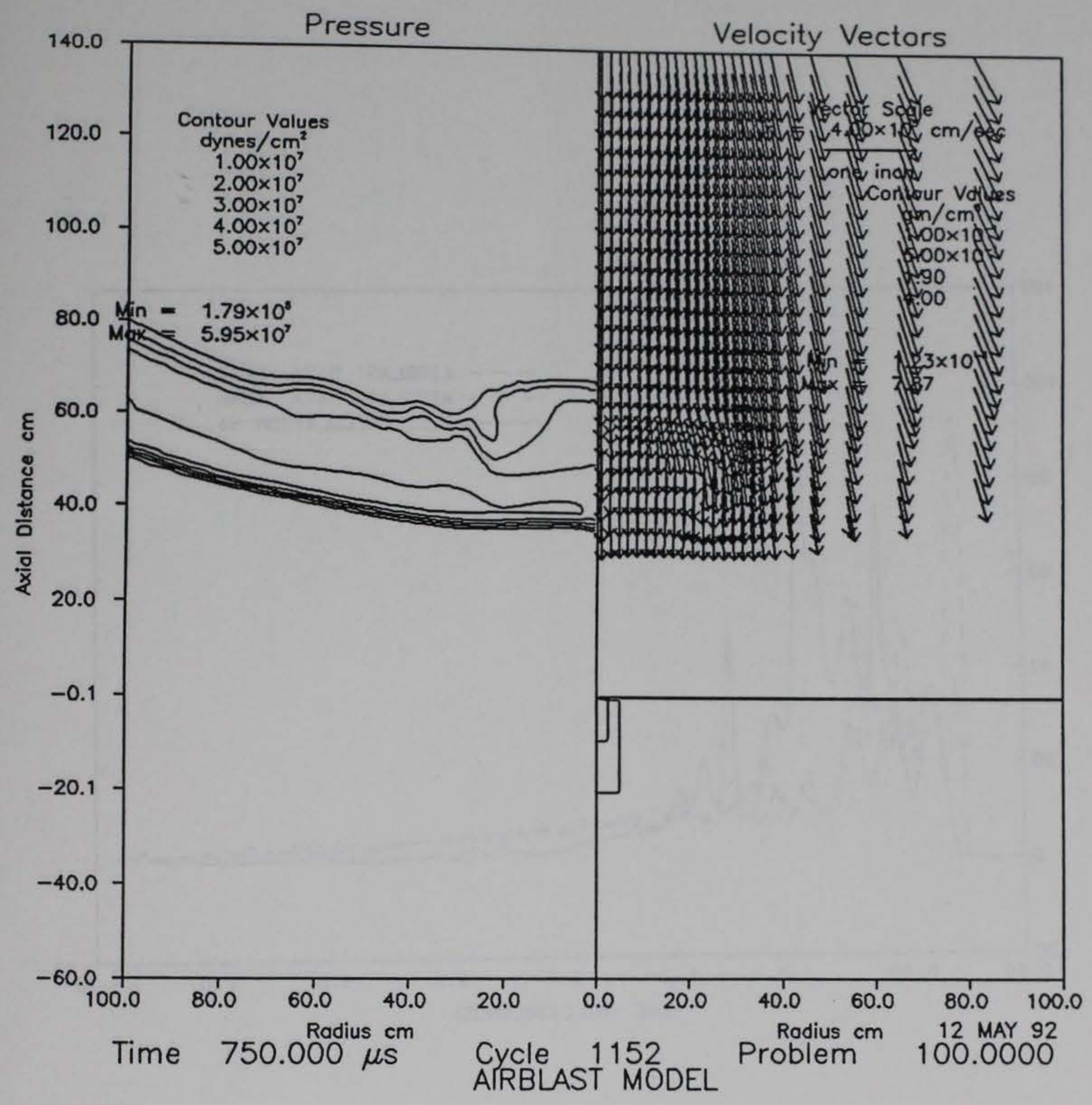

Figure 9. Split Panel Plots for Test Calculation No. 4 (specific energy equation modified) 


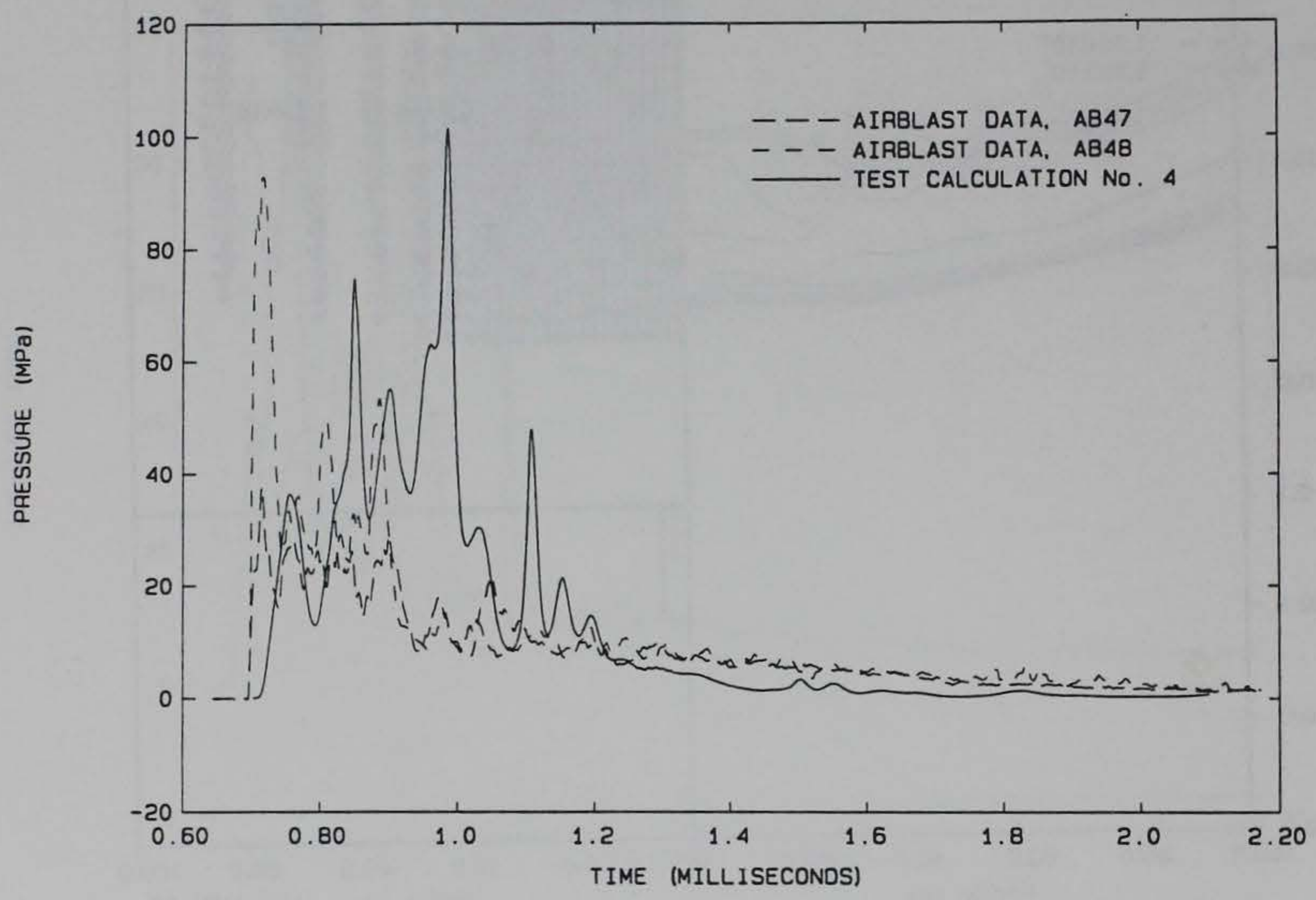

Figure 10. Station Plot at Ground Zero for Test Calculation No. 4 


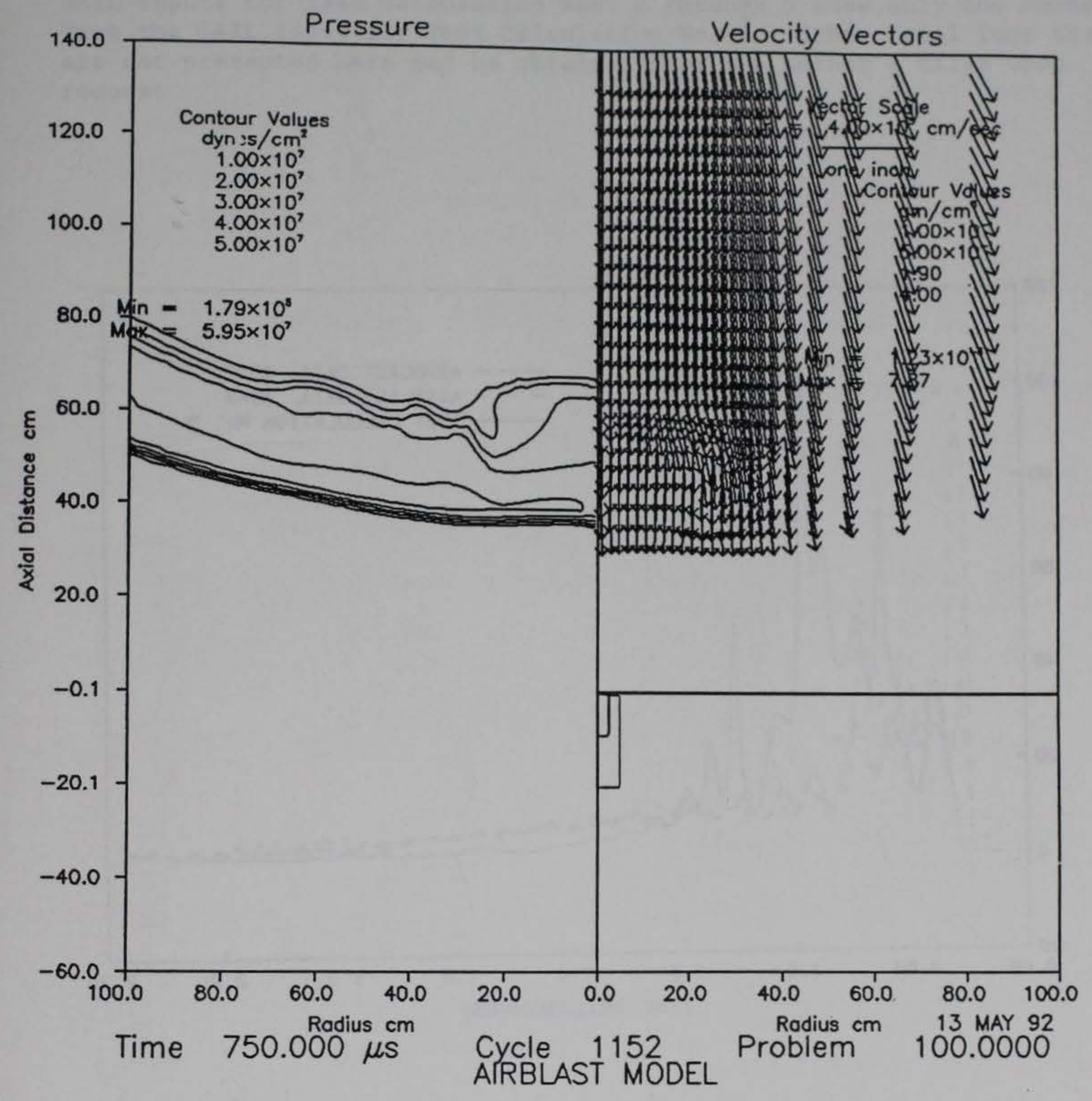

Figure 11. Split Panel Plots for Test Calculation No. 5 (specific energy and velocity equations modified) 


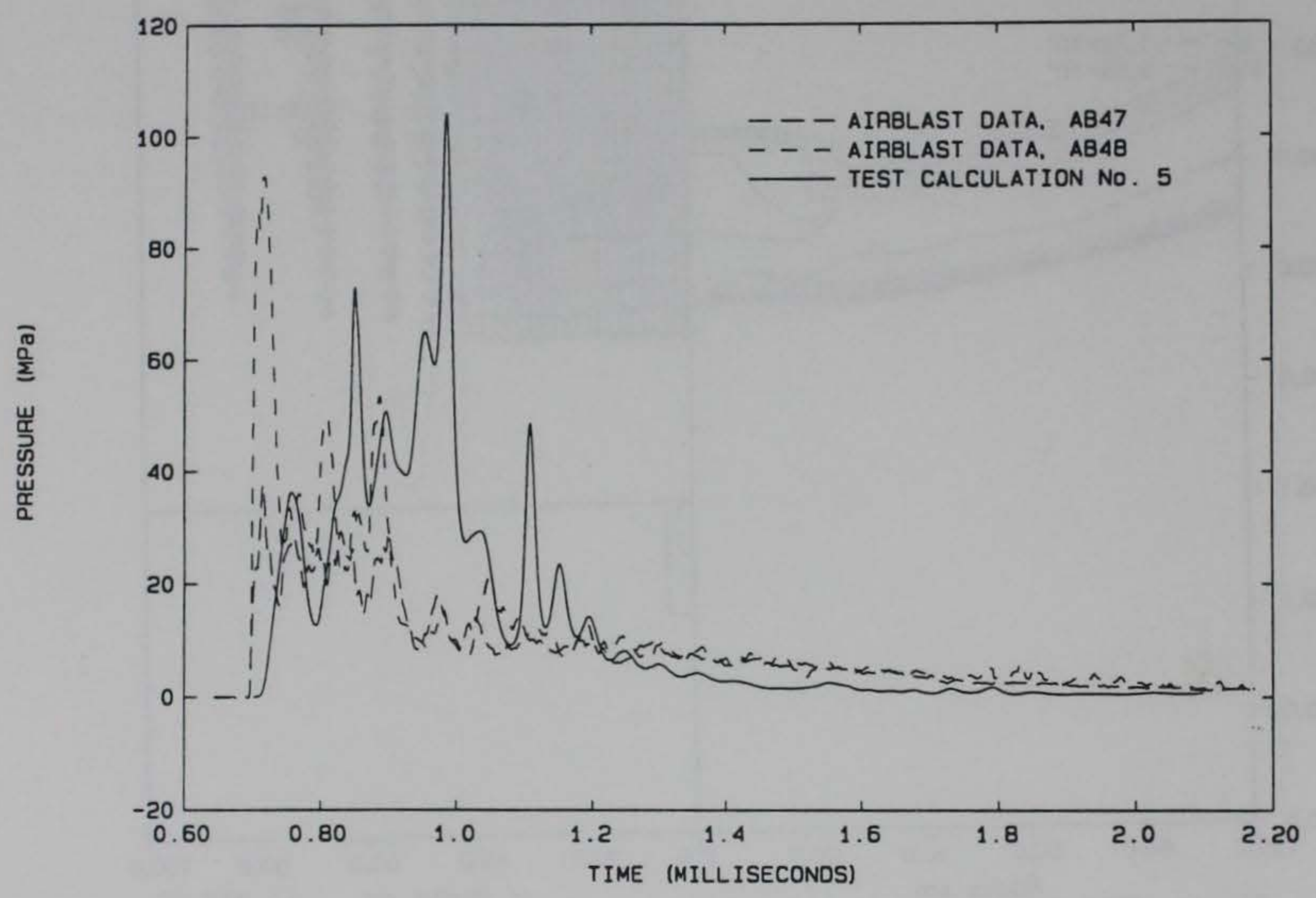

Figure 12. Station Plot at Ground Zero for Test Calculation No. 5 


\section{Appendix: SAIL Input for Figures 3 through 12}

This appendix shows the sail commands for the run of each of the five test cases presented earlier (Figures 3 through 12). Each two consecutive figures were obtained as a result of a set of new SAIL commands in two HULL batch run and starting with Figure 3 . Note that SAIL inputs for Test Calculation Nos. 2 through 5 show only the changes from the SAIL input for Test Calculation No. 1 . Other trial runs that are not presented here may be obtained from the author's files upon request. 


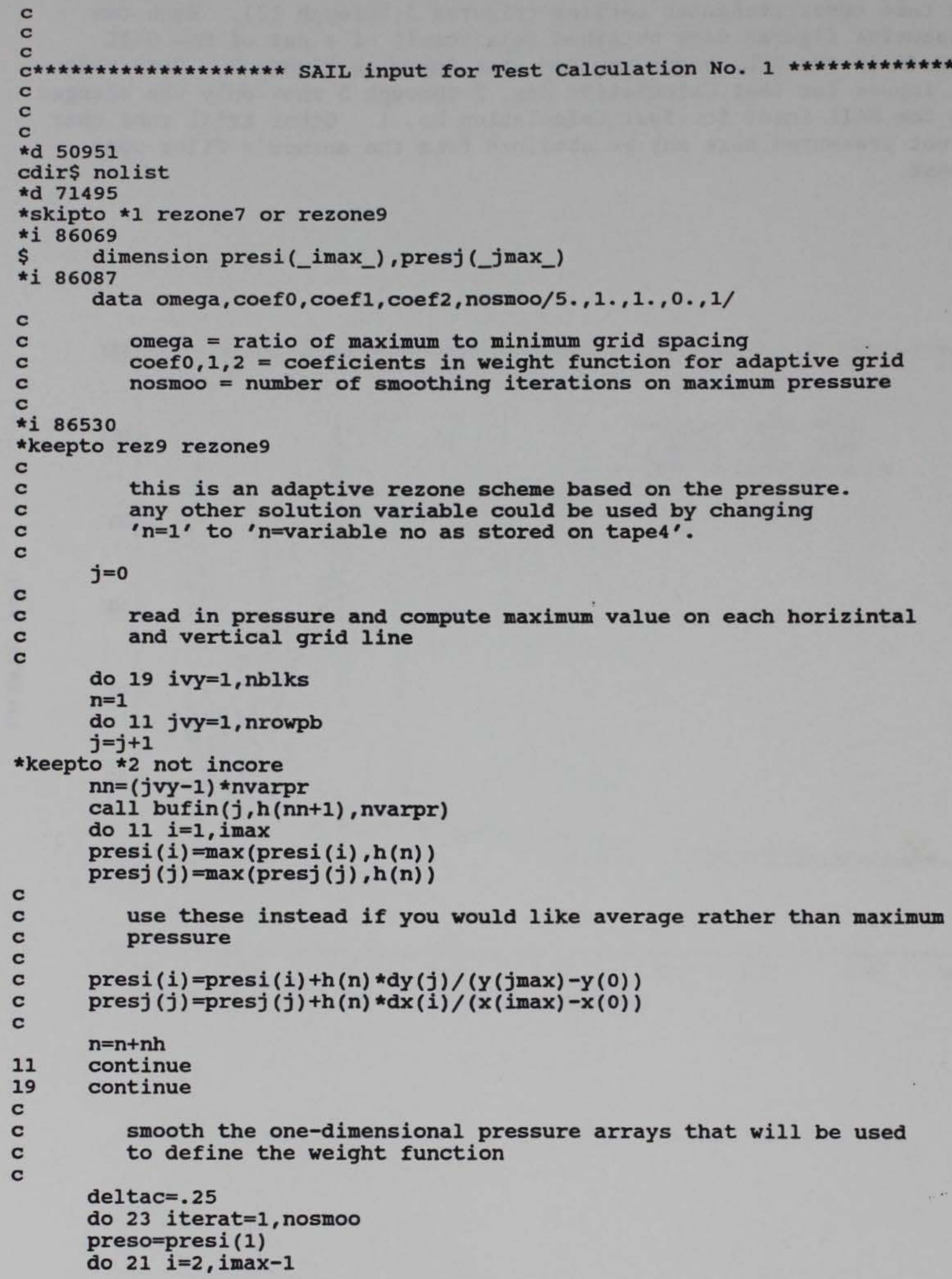

c

c

c

c

c

c

11

19

c

c

c

c 


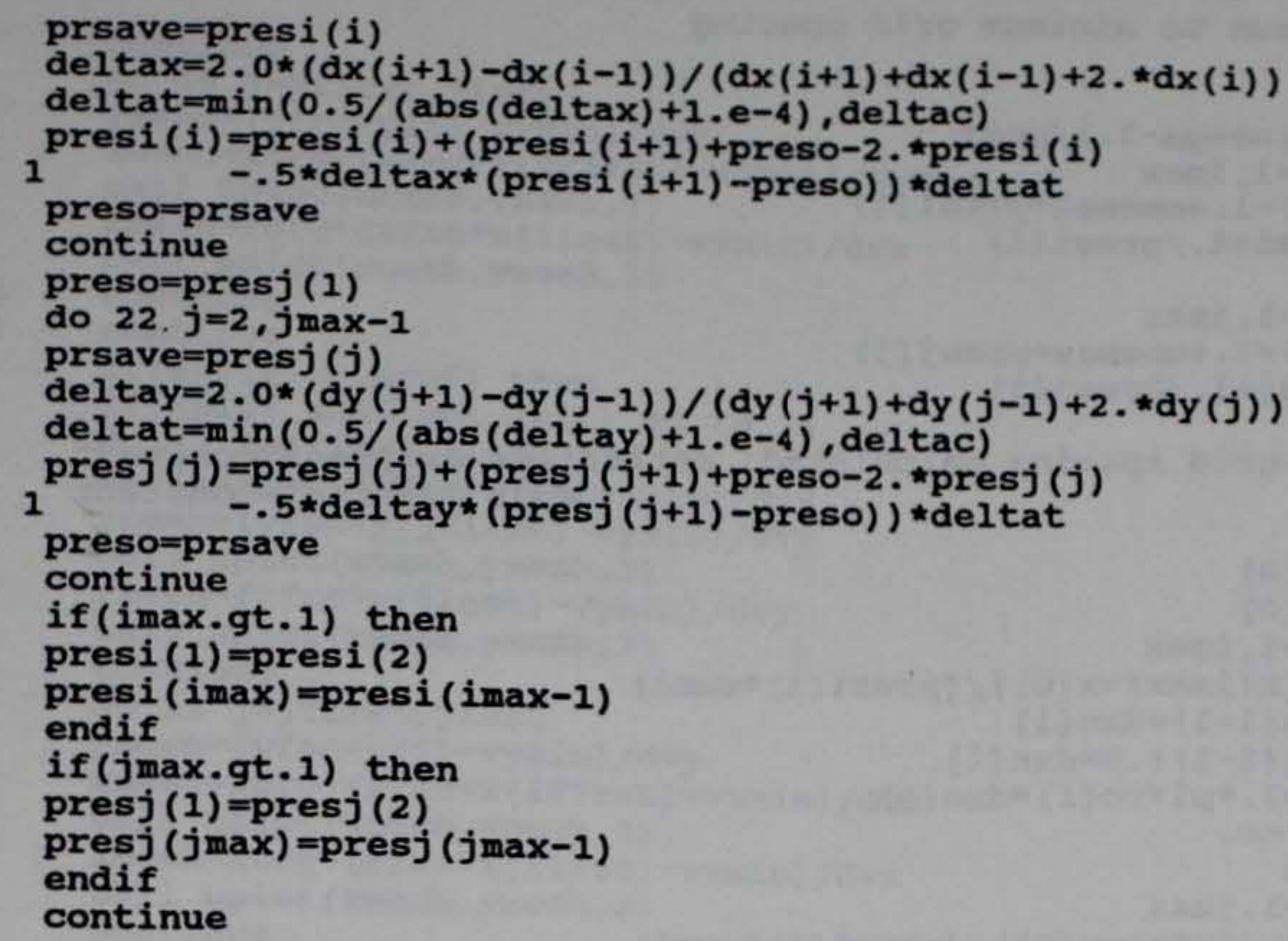

continue

if (imax.gt.1) then

presi (1) =presi (2)

presi $(i \max )=$ presi $(i \max -1)$

endif

if (jmax.gt.1) then

presj (1)=presj (2)

presj $(j \max )=\operatorname{presj}(j \max -1)$

endif

continue

smoothing completed, now define the weight function and put those values in arrays presi and presj

$\operatorname{pmax}=0$.

preso=presi (1)

do $12 i=2, i \max -1$

prsave $=$ presi (i)

deltax $=d x(i+1)+2 . * d x(i)+d x(i-1)$

presi $(i)=$ coefo*presi $(i)+\operatorname{coef} 1 * a b s(p r e s i(i+1)-p r e s o) /$ deltax 1 +4 . *coef 2 *abs (presi $(i+1)+$ preso-2.*pres $i(i)$

$2-(d x(i+1)-d x(i-1)) \star(\operatorname{pres} i(i+1)-p r e s o) / \operatorname{deltax}) /(\operatorname{deltax}) \star \star 2$ pmax $=\max$ (pmax, presi(i))

12 continue

if (imax.gt.1) then

presi $(i \max )=$ presi $(i \max -1)$

presi (1) $=$ presi (2)

endif

preso=presj (1)

do $13 j=2, j \max -1$

prsave $=$ presj $(j)$

deltay $=d y(j+1)+2 . * d y(j)+d y(j-1)$

presj $(j)=$ coefo*presj $(j)+$ coef 1 *abs (presj $(j+1)$-preso)/deltay 1 +4. *coef 2 *abs (presj $(j+1)+$ preso-2. *pres $j(j)$

$2-($ dy $(j+1)-d y(j-1)) *($ presj $(j+1)-$ preso $) /$ deltay $) /($ deltay $) \star 2$ $\operatorname{pmax}=\max (\operatorname{pmax}, \operatorname{pres} j(j))$

13 continue preso=prsave

if (jmax.gt.1) then

presj (1)=presj (2)

presj $(j \max )=$ presj $(j \max -1)$

endif

c

weight function is modified to produce desired ratio of 
sumi $=0$.

omemax $=($ omega-1.) $/$ pmax

do $14 i=1$, $i \max$

presi $(i)=1$. +omemax*presi (i)

14 sumi $=$ sum $i+1 . / p r e s i(i)$

sumj $=0$.

do $15 j=1, j \max$

presj $(j)=1 .+$ omemax*presj $(j)$

15

sumj=sumj+1./presj (j)

new grid spacing calculated; satisfies: $d x *$ pres $i=c o n s t a n t$ and: $d y \star$ pres $j=$ constant

c

C

16

$$
\begin{aligned}
& x n(0)=x(0) \\
& y n(0)=y(0)
\end{aligned}
$$

do $16 i=1$, $i \max$

$d x n(i)=(x(i \max )-x(0)) /(\operatorname{pres} i(i) *$ sumi $)$

$\operatorname{xn}(i)=\operatorname{xn}(i-1)+\mathrm{dxn}(i)$

$\operatorname{rc}(i)=x n(i-1)+.5 \star d x n(i)$

$\operatorname{taun}(i)=2 . * p i * r c(i) * d x n(i)$

$$
\text { presi } i)=0 \text {. }
$$

$$
\text { continue }
$$

do $17 j=1, j \max$

$\operatorname{dyn}(j)=(y(j \max )-y(0)) /(\operatorname{presj}(j) \star$ sumj $)$

$\operatorname{yn}(j)=\operatorname{yn}(j-1)+\operatorname{dyn}(j)$

17

$$
\text { presj }(j)=0 \text {. }
$$

*label rez9

*i 120720

*i 121521

common/unit/nunit

i 130127

\section{nunit $=66$}

open (nunit, file='plot.dat')

$c$
$c$
$c$
$c$
$c$
$c$
$c$
$c$
$c$
$c$

with this addition, when pcell=.true., the grid is plotted (as well as the cell indices along the plot border). since plotting cell indices is the default, you must use the parameter 'nocells' in your plot statements if you do not want a grid: for example, 'pcont ( nocells )'.

it has been noted that when pref=.true., the grid line along the axis is plotted twice and that grid line therefore looks darker than the other lines.

if (pcell) then

ifirst=iminbd-1

ilast $=$ imaxbd

jfirst=jminbd-1

jlast $=j$ maxbd

xorg $=0$.

if (pref.or.split) $x$ org $=x l l$

if (split.and.left) go to 11

do 9 i=ifirst, ilast

xmesh=xorg $+(x$ fac $* x(i)-v x m i n) / d v x$

ymesh $=(y$ fac*y (jfirst) $-v y m i n) / d v y$

call uplot (xmesh, ymesh, 3 )

ymesh $=(y$ fac*y (jlast) - vymin $) /$ dvy

call uplot (xmesh, ymesh, 2) 
continue

do $10 j=j$ first, jlast

ymesh $=(y$ facky $(j)-v y m i n) / d v y$

xmesh $=x$ org $+($ xfac*x (ifirst) $-v x m i n) / d v x$

call uplot (xmesh, ymesh, 3 )

xmesh $=x$ org $+(x f a c \star x($ ilast $)-v x m i n) / d v x$

10 continue

if (split.or.pref) then

if (split.and..not.left) go to 14

do 12 i=ifirst, ilast

xmesh=xorg- $(x f a c * x(i)-v x m i n) / d v x$

ymesh $=(y$ facky (jfirst) $-v y m i n) / d v y$

call uplot (xmesh, ymesh, 3 )

ymesh $=(y$ fac*y $(j$ last $)-v y m i n) / d v y$

12 continue

do $13 j=j$ first, $j$ last

ymesh $=(y$ fac*y $(j)-v y m i n) / d v y$

xmesh=xorg $-($ xfac*x (ifirst) $-v x m i n) / d v x$

call uplot (xmesh, ymesh, 3 )

xmesh=xorg $-($ xfac $* x($ ilast $)-v x m i n) / d v x$

call uplot (xmesh, ymesh, 2)

13 continue

14 continue

endif

endif

*d 134919,134925

*d 134925.2 


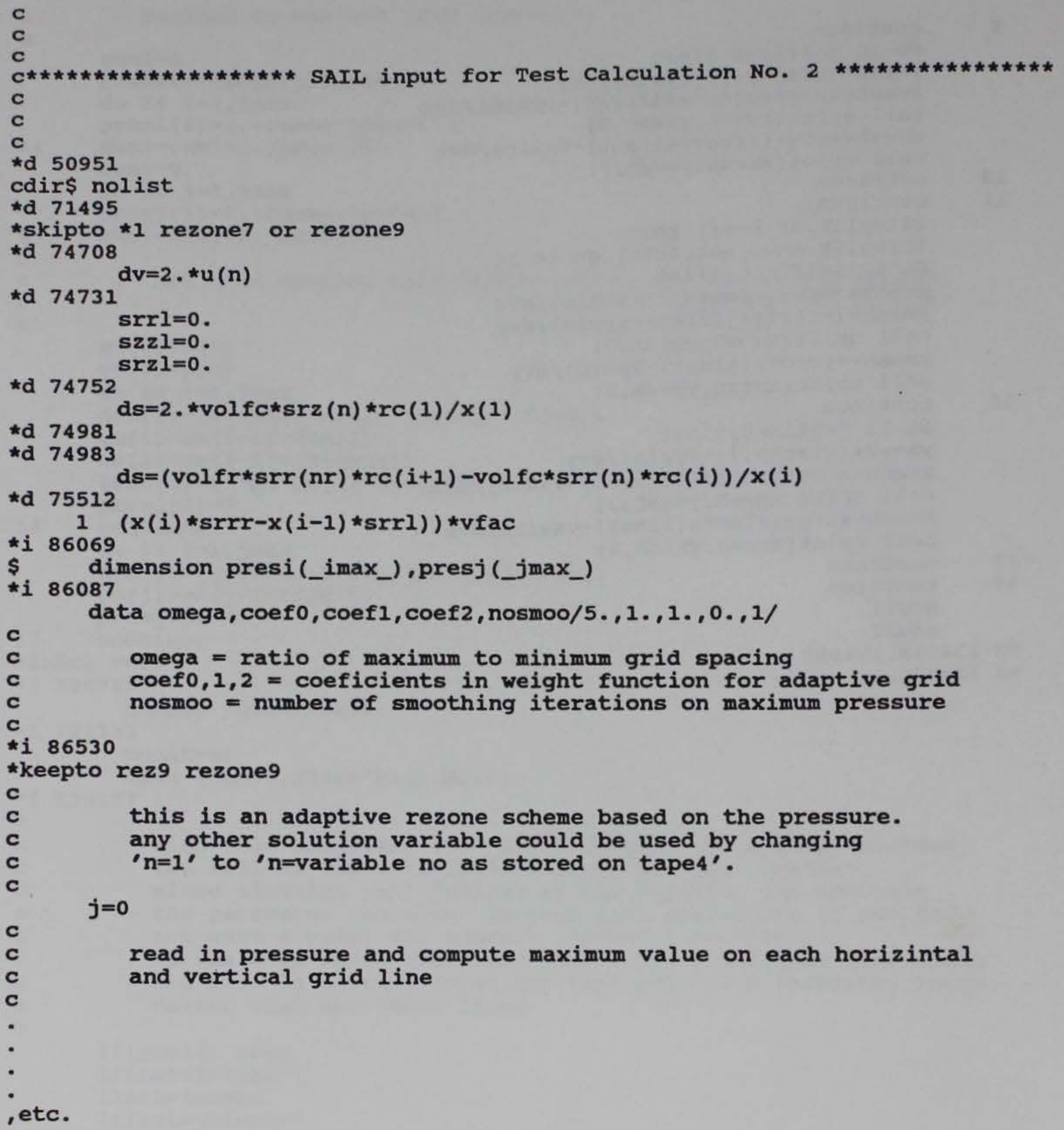




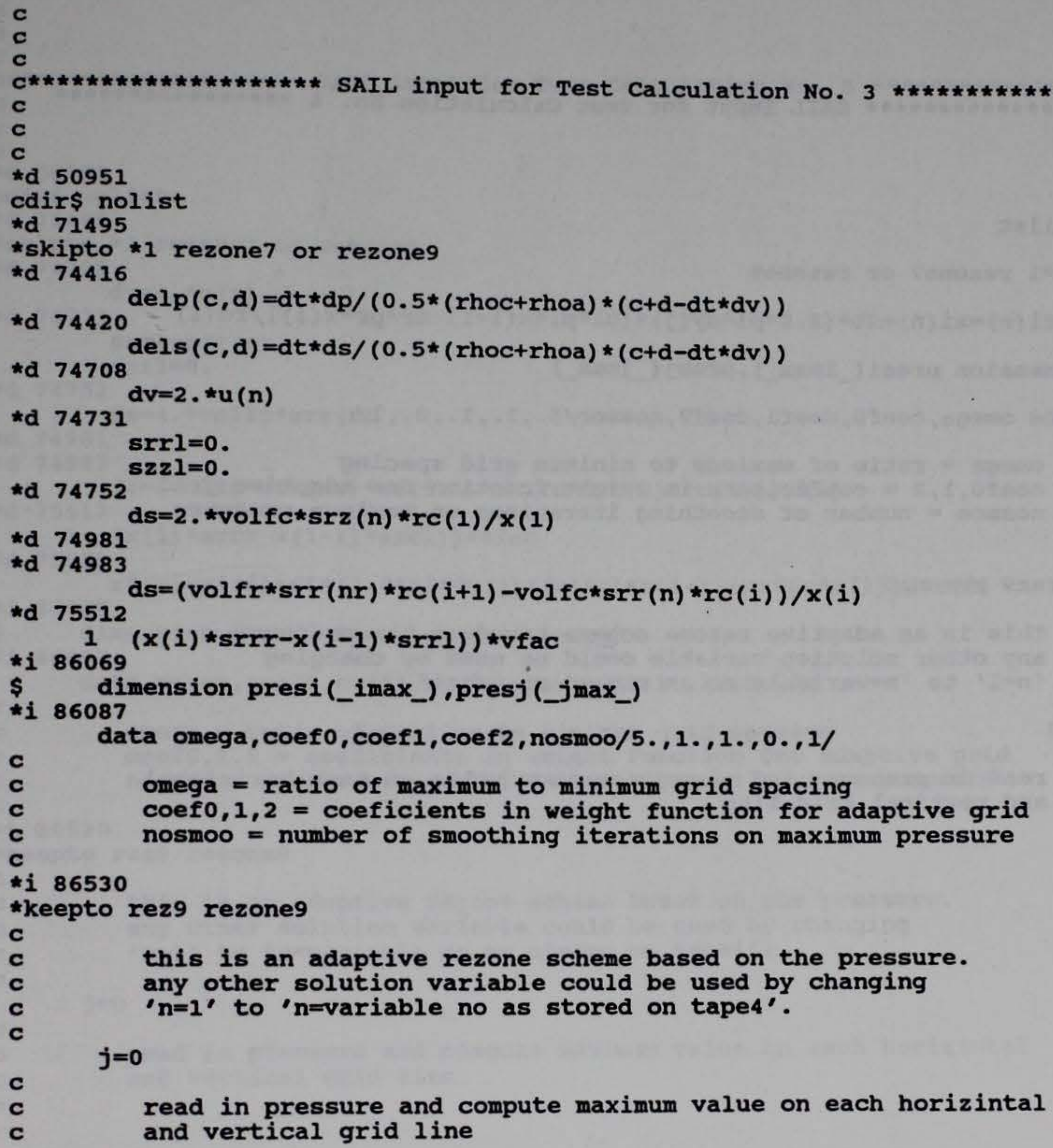




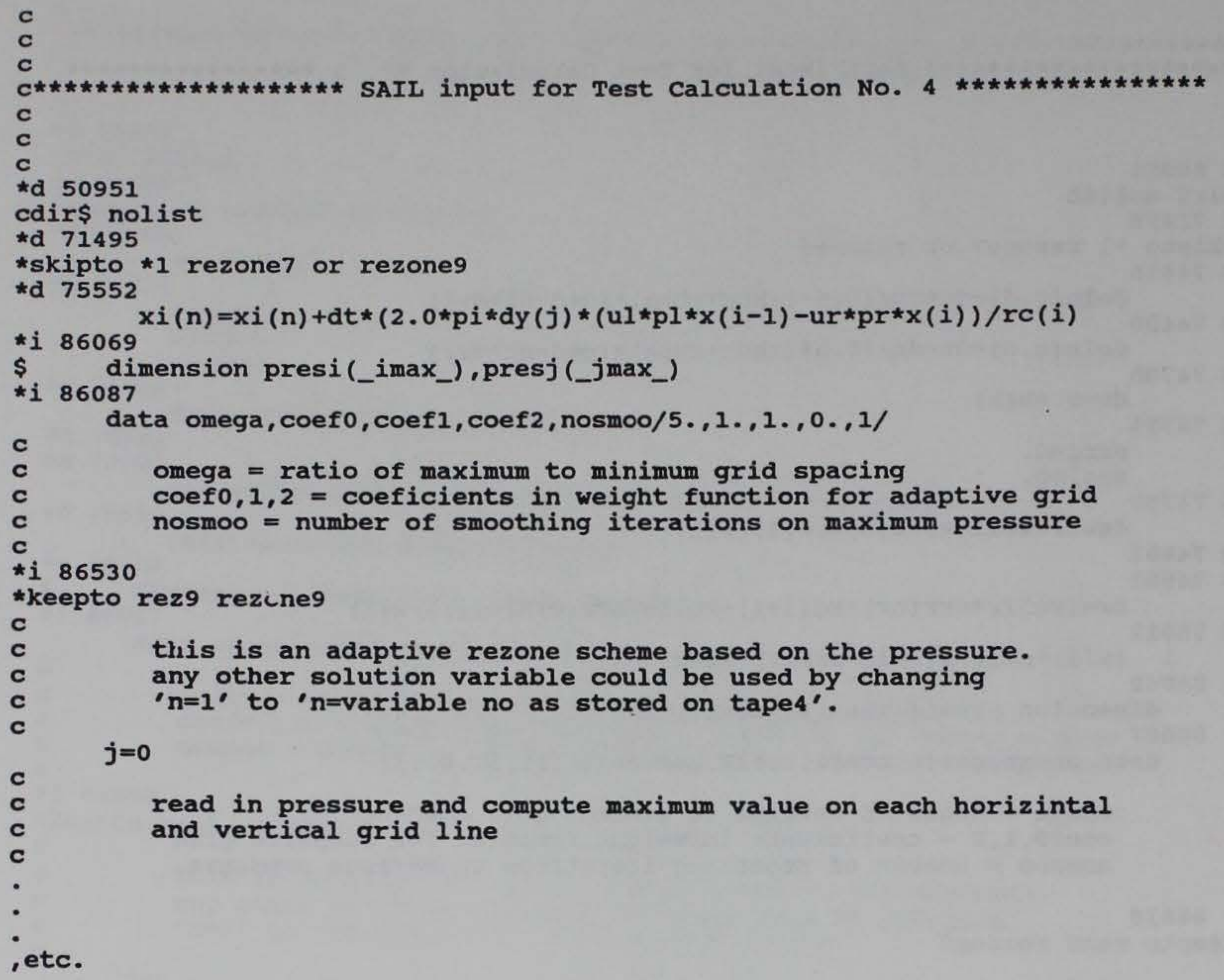




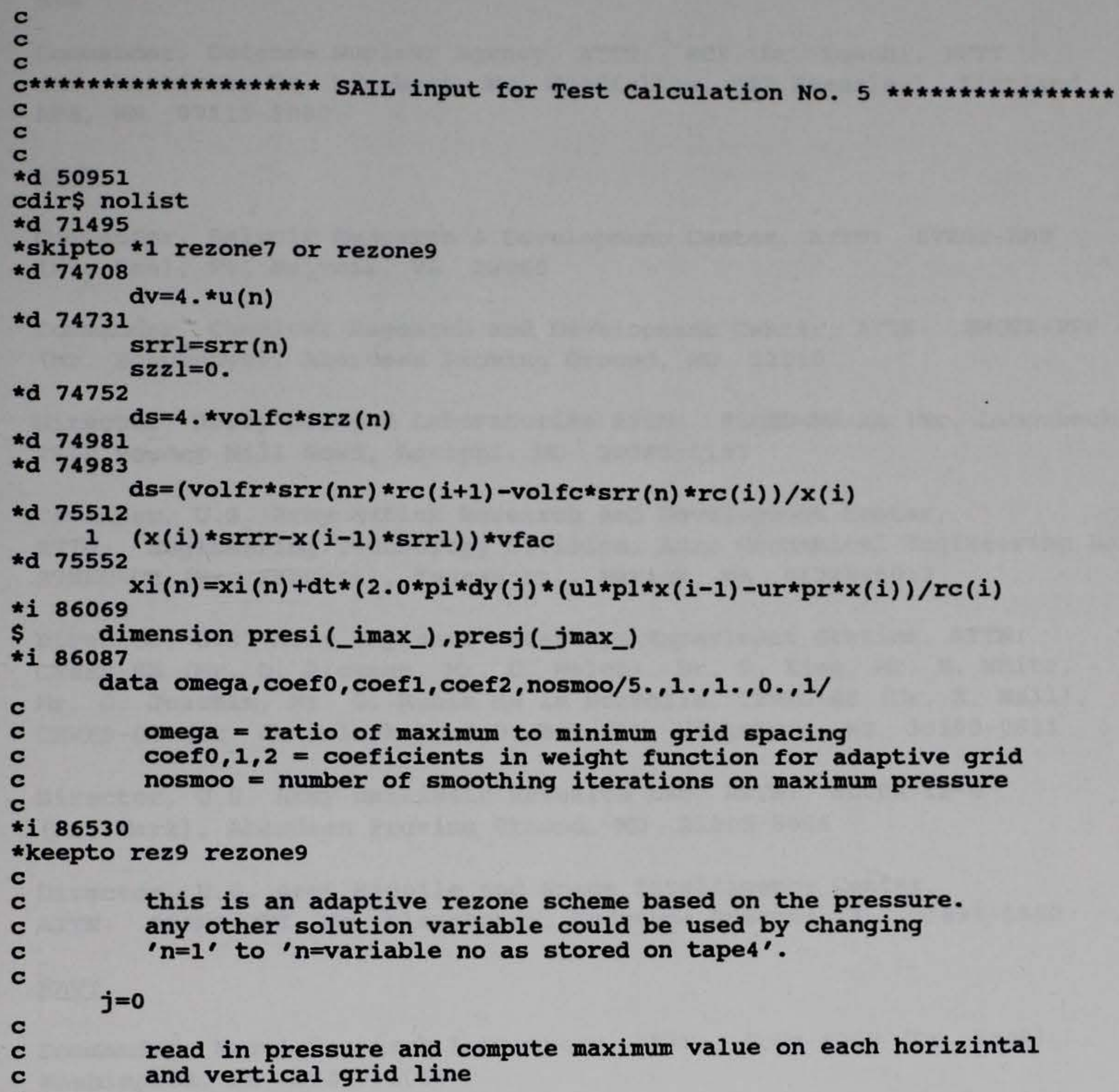


DOD

Commander, Defense Nuclear Agency, ATTN: FCX (Dr. Leech), FCTT

(Mr. Martinez, Dr. Rinehart, Mr. Goodfellow, CPT Roessler), Kirtland AFB, NM 87115-5000

\section{$\underline{\text { ARMY }}$}

Commander, Belvoir Research \& Development Center, ATTN: STRBE-EMP (Mr. Ess), Ft. Belvoir, VA 22060

Commander, Chemical Research and Development Center, ATTN: SMCCR-PPP (Mr. Schumchyk), Aberdeen Proving Ground, MD 21010

Director, Harry Diamond Laboratories ATTN: SLCHD-NW-RA (Mr. Lingebach), 2800 Powder Mill Road, Adelphi, MD 20783-1197

Commaner, U.S. Army Natick Research and Development Center, ATTN: Engineering Technology Division, Aero Mechanical Engineering Lab STRNC-UE (Mr. Fanucci), Kansas St., Natick, MA 01760-5019

Director, U.S. Army Engineer Waterways Experiment Station, ATTN: CEWES-SE (Mr. D. Rickman, Mr. C. Welch), Dr. P. King, Mr. H. White, Mr. C. Joachim, Mr. G. Rubin de la Borbolla, CEWES-SS (Dr. R. Hall), CEWES-SD (Dr. J. Zelasko), P.O. Box 631, Vicksburg, MS 39180-0631

Director, U.S. Army Ballistic Research Lab, ATTN: SLCBR-TB-B (Dr. Mark), Aberdeen Proving Ground, MD 21005-5066

Director, U.S. Army Missile and Space Intelligence Center, ATTN: AIAMS-YTT (Mr. Blanchard), Redstone Arsenal, AL 35898-5500

NAVY

Commander, Naval Research Laboratory, ATTN: Code 4040 (Dr. Book), Washington, DC 20375-5000

Commander, Naval Weapons Center, ATTN: Code 326 B, China Lake, CA 93555

Commander, Naval Surface Weapons Center, White Oak, ATTN: R15 (Mr. Swisdak), Silver Spring, MD 20910-5000

\section{OTHER GOVERNMENT AGENCIES}

Los Alamos National Laboratory, ATTN: Code ESS-7 (Mr. Jocobson), MS D466, Los Alamos, NM 87545

Sandia National Laboratories, Albuquerque, ATTN: Code 315 (Mr. T. Herther), Albuquerque, NM 87185 
Aberdeen Research Center, ATTN: Mr. Keefer, P.O. Box 548, Aberdeen, MD 21001

Carpenter Research Corporation, ATTN: Mr. Carpenter, P.O. Box 2490, Rolling Hills Estate, CA 90274

California Research and Technology, Inc., ATTN: Mr. J. Thomsen, 5117 Johnson Drive, Pleasanton, CA 94566

Director, New Mexico Engineering Research Institute/CERF, ATTN: Dr. Baum, Kirtland AFB, NM 87115

Research \& Development Associates, ATTN: Dr. Kuhl, P.0. Box 9695 , Marina del Rey, CA 90291

Research \& Development Associates, ATTN: Dr. Ganong, P.0. Box 9335 , Albuquerque, NM 87119

S-Cubed, ATTN: Mr. Needham, P.O. Box 8243, Albuquerque, NM 87198

Tech Reps Inc., ATTN: Mr. F. McMullan, 5000 Marble Avenue, NM, Suite 222, Albuquerque, NM 87110 
Public reporting burden for this collection of information is estimated to average 1 hour per response, including the time for reviewing instructions. searching existing data sources. gathering and maintaining the data needed, and completing and reviewing the collection of information. Send comments regarding this burden estimate or any other aspect of this Davis Highway. Suite 1204, Arlington, VA 22202-4302, and to the Office of Management and Budget, Paperwork Reduction Project (0704-0188), Washington, DC 20503.

\section{TITLE AND SUBTITLE} July 1993

\section{Final Report from 11-25-91 to 5-24-92}

Centerline Discrepancies In

HULL Axisymmetric Calculations

6. AUTHOR(S)

Amitabha Ghosh

5. FUNDING NUMBERS

Contract No. :

DACA39-91-C-0034

TCN 92-007 Delivery

Order 0084 - MIPR

HD 1102-1-H24A03

7. PERFORMING ORGANIZATION NAME(S) AND ADDRESS(ES)

and $H D$ 1102-1- $442 \mathrm{KO} 3$

Dr. Amitabha Ghosh

8. PERFORMING ORGANIZATION REPORT NUMBER

Rochester Institute of Technology

One Lomb Memorial Drive

Rochester, NY 14623

9. SPONSORING/MONITORING AGENCY NAME(S) AND ADDRESS(ES)

Defense Nuclear Agency,

Kirtland AFB, NM 87117-5000;

U.S. Army Engineer Waterways Experiment Station

Structures Laboratory, 3909 Halls Ferry Road

Vicksburg. Mississippi 39180-6199

\section{SUPPLEMENTARY NOTES}

Task was performed under a Scientific Services Agreement issued by Battelle,

Research Triangle Park Office, 200 Park Drive, P.0. Box 12297, RTP, NC 227709

12a. DISTRIBUTION/AVAILABILITY STATEMENT

12b. DISTRIBUTION CODE

Approved for public release, distribution unlimited

13. ABSTRACT (Maximum 200 words)

Axisymmetric calculations using the HULL hydrocode exhibit peculiar jetlike artifacts near the axis of symmetry. A series of numerical experiments were performed to determine the cause of this behavior. Governing equations and boundary conditions in the HYDRO subroutine were modified and tested. Results show considerable improvements of the artifacts. Calculations were performed with an airblast model and compared with experimental data and previous calculations.

Airblast calculations, Axisymmetric flows

Boundary conditions, HULL hydrocode

17. SECURITY CLASSIFICATION OF REPORT

UNCIASSIFIED
SECURITY CLASSIFICATION

OF THIS PAGE

UNCLASSIFIED
19. SECURITY CLASSIFICATION OF ABSTRACT

UNCLASSIFIED 